\title{
O Desejo ao Rés do Chão: Apontamentos para uma Educação Espacializada ${ }^{1}$
}

\author{
Ulysses da Cunha Baggio²
}

Resumo: Este artigo se propõe a uma reflexão crítica sobre o papel e o sentido da educação na contemporaneidade, tratando-se mais especificamente de um horizonte político para a educação, que incorpore e valorize a dimensão espacial em seus propósitos maiores. Abre-se a perspectiva quanto à formação de uma educação espacializada para a vida e a liberdade tanto quanto ela seja possível, acompanhada de um sólido senso de responsabilidade socioespacial.

Palavras-chave: educação espacializada; desejo; liberdade; autonomia

\section{The Desire to Level of the Soil: notes for an education spatializing}

\begin{abstract}
This article aims at a critical reflection on the role and meaning of education in contemporariness, more specifically in the case of a political horizon for education, which incorporates and enhances the spatial dimension in their larger purposes. It opens up the prospect on the formation of an education spatializing to life freedom as much as it is possible, accompanied by a strong sense of sociospatial responsibility.
\end{abstract}

Keywords: education; education spatializing; desire; freedom; autonomy

\section{INTRODUÇÃO}

\begin{abstract}
"A sociedade livre se estabelece pela liberdade alcançada, no seu desenvolvimento completo, a cada pessoa humana, primeira célula fundamental, que se agrega em seguida e se associa, como lhe agrada, às outras células da mutável humanidade. É na proporção direta dessa liberdade e desse desenvolvimento inicial do indivíduo que as sociedades ganham em valor e nobreza: é do homem que nasce a vontade criadora que constrói e reconstrói o mundo." (Elisée Reclus)
\end{abstract}

Esse trabalho se propõe a uma reflexão acerca da educação, mais propriamente de uma educação para a contemporaneidade, que valorize e incorpore a dimensão espacial da realidade social em suas preocupações maiores, em suas abordagens e propósitos. Não é nosso interesse, em seus limites, explorar as especificidades de orientação de suas escolas, mas sim submeter à crítica certos aspectos e situações de caráter mais geral da educação, na busca de outros horizontes à sua realização na sociedade, sob uma perspectiva que se pretende pertinente às condições do mundo atual, em face das profundas transformações

\footnotetext{
${ }^{1}$ Este artigo está vinculado ao projeto de pesquisa autônomo que ora desenvolvo no Departamento de Geografia da UFV, desde setembro de 2007, intitulado "Território e sociedade no horizonte de uma geografia libertária: percursos de uma epistemologia do desejo".

${ }^{2}$ Doutor em Geografia Humana pela Universidade de São Paulo; Professor do Departamento de Geografia da UFV.

Endereço postal: Rua Tiradentes, 184, apto. 202, bairro: João Braz. CEP: 36570-000 - Viçosa, MG. e-mail: ulybaggio@ufv.br.
} 
verificadas na experiência humana e nas práticas sociais. Trata-se de um mundo submetido aos influxos de uma globalização capitalista acelerada e, de forma correlacionada, de novas dinâmicas de urbanização e reestruturação socioespacial, que impactam profundamente a vida e a existência, conformando-as. É justamente sob esta condição de uma maior espacialização do processo social que oferecemos essa reflexão.

Assim, pensando sobre o sentido e o papel da educação na contemporaneidade, inclinamonos a defender a idéia de que ela deva recobrir uma pedagogia genuinamente relacional, que solicite o viver intelectual, estimulando nas pessoas o desejo de se tornarem co-autores do saber, um saber capaz de iluminar práticas sociais que perquiram a superação do estado de barbárie e seus impulsos destrutivos na sociedade (condição fundamental à sobrevivência da humanidade), ao mesmo passo que da banalização generalizada e, nesse sentido, operando ativa e decisivamente em prol da libertação dos homens do modelo de dominação e controle do sistema capitalista global, revogando suas estruturas de condicionamento. Estas práticas se orientariam à criação de um valor calcado na afetuosidade e no respeito mútuo entre as pessoas, de modo a não reduzir a vida humana ao valor, ou ainda, à economia e suas leis, que conflitam e se opõem à totalidade da vida. Ao mesmo passo se devotariam à promoção da virtude cooperativa entre elas, atuando pela combinação qualitativa das diferenças na busca de uma condição social mais democrática, digna e saudável. Essa perspectiva recobre, assim, o plano mental e psicológico e a realidade prático-sensível dos sistemas sociais.

Por outro lado, temos que o sistema escolar vigente se organiza em torno de um critério essencialmente produtivista, plenamente enquadrado na lógica da mercadoria e do mercado e, desse modo, operando sob a proeminência das quantidades e da meritocracia, fazendo introjetar nas mentes a idéia de que a competição é a virtude maior na vida social, alimentando, assim, uma leitura da sociedade como sendo constituída de "incluídos" e os demais ("excluídos" e/ou precária ou perversamente inseridos), ou seja, uma concepção que carrega na origem a marca da desigualdade, que estimula toda forma de preconceito. 0 ambiente daí constituído é o de uma disputa obsessiva entre alunos, professores, funcionários, dando-nos a imagem de uma arena de seres automáticos em pleno exercício competitivo sob a brisa do darwinismo social, movidos pela imposição da necessidade de resultados. 
Sob esta condição, os saberes transmutam-se em artigos de consumo, isto é, em mercadorias, levando o conhecimento a se converter em objeto de negócios, em matéria para empreendedores, a produzir e a dispor - mais e mais, cada vez mais - essa tão valorizada mercadoria. Como um recurso o conhecimento se torna uma variável poderosa no "clássico processo" em que "os detentores de recursos competem vantajosamente com os que deles não dispõem". (SANTOS, 1996, p.194). Temos, dessa forma, a instauração do reino do saber mensurado e administrado, um saber gerido em moldes empresariais, em que a produção do conhecimento não se restringe mais e fundamentalmente à universidade, especialmente a pública, embora nestas a produtividade do trabalhado docente e de pesquisadores tenha aumentado significativamente, acompanhado de um expressivo crescimento do número de alunos de graduação e pós-graduação. No que tange às instituições privadas, talvez elas, de modo geral, não se qualificassem propriamente como universidades, dado que aí a pesquisa e a produção do conhecimento é muito restrita, funcionando mais como fábricas de diplomas ou colégios de terceiro grau, salvo algumas exceções, tais como as PUCs, que apresentam certo destaque na produção científica do país. De resto, temos um rol de centros universitários que operam mais no ensino, e de faculdades isoladas que proporcionam uma formação mais imediata, de qualidade e alcance social bastante discutíveis.

No reino do saber empresarial, os que são ou se pretendem críticos, freqüentemente são alvo de discriminações, rotulados de improdutivos, desocupados, manifestações que partem, na maioria das vezes, de segmentos sociais plenamente absorvidos pela lógica do mercado e da mercadoria, não raro advogando uma visão imediatista e instrumental da realidade, expondo uma mentalidade contábil e mercantil, que propugna os arquétipos do ter e do parecer. Este estéril cenário faz reduzir substancialmente o horizonte da crítica mais profunda, podendo-se destacar a do problema das conformações que o conhecimento assume na sociedade sob o desenvolvimento do capitalismo, conduzindo à naturalização de situações sociais. Ao mesmo tempo eles se deparam com certos limites impostos pela racionalidade burocrática, que modela práticas de trabalho mortificantes, que obstruem a criatividade e a liberdade na produção das idéias. Dentre outras manifestações, temos professores, funcionários e alunos administrando o uso regular de medicamentos para favorecer a concentração, relaxamento e sono. Da mesma forma, aos que têm filhos, tem sido cada vez mais comum só se poder vê-los à noite. Essa situação carrega o sentido de uma 
crise, que não recobre apenas a realidade universitária, mas se estende ao ensino básico e fundamental, público e privado, no qual recaem profundas carências quanto à formação docente bem como condições institucionais adequadas ao efetivo desenvolvimento e qualidade do ensino.

Estaríamos, assim, diante de um efetivo sistema de enquadramento e adaptação, de caráter produtivista, burocrático e redutor, que constrange a autonomia, desvaloriza o saber crítico e ofusca a possibilidade de vias e formas alternativas, fazendo da história uma via de mão única, submetida aos imperativos de uma lógica mercantil e monetária.

Este sistema conta com uma base de sustentação que nem sempre é reconhecida ou levada em devida conta, isto é, o próprio território, e seu acólito maior representado pelo urbanismo moderno capitalista, meio eficaz que ao articular tempo e espaço, sob a lógica e o poder da acumulação capitalista, modela a realidade e as subjetividades e, dessa forma, suas próprias representações, influenciando-as. Ele estabelece uma forma social capitalista de relacionalidade que está na base de uma efetiva educação capitalista do espaço, bastante difundida na sociedade, sobretudo no que concerne ao desenvolvimento do meio urbano. Desse modo, tal desenvolvimento se conformaria como

[...] a escolha de uma certa materialização do possível, com a exclusão de outros. Como a estética, da qual ele vai seguir o movimento de decomposição, ele pode ser considerado como um ramo bastante negligenciado da criminologia. Entretanto, o que o caracteriza no nível do "urbanismo", em relação a seu nível simplesmente arquitetural, é o fato de exigir um consentimento da população, uma integração individual no desencadeamento desta produção burocrática do condicionamento.

Tudo isto é imposto por meio da chantagem da utilidade. Esconde-se que a importância completa desta utilidade é colocada a serviço da reedificação.

O capitalismo moderno faz renunciar a toda crítica pelo simples argumento que é preciso um teto, da mesma forma que a televisão se afirma sob o pretexto de que é preciso informação, divertimento. Levando a negligenciar a evidência que esta informação, esta diversão, este modo de habitat não são feitos para as pessoas, mas sem elas, contra elas.

Toda planificação urbana se compreende somente como campo da publicidadepropaganda de uma sociedade, isto é, a organização da participação em qualquer coisa que é impossível participar. (KOTANYI; VANEIGEM, 1997, p.1).

Com um discurso arrogante e auto-suficiente, os adeptos e defensores desse sistema promovem o enaltecimento da cultura do mercado, do consumo e do dinheiro, tornados meios e fins absolutos, difundindo massivamente o ideal da capitalização possível num cenário midiaticamente forjado de oportunidades e ganhos sociais. Pode-se compreender, assim, que 
"No capitalismo, a atividade econômica, o sucesso, as vantagens materiais passam a ser fins em si mesmos. $O$ destino do homem torna-se contribuir para o crescimento do sistema econômico, ajuntar capital, não tendo em vista sua própria felicidade ou salvação, mas como um fim por si mesmo. O homem converteu-se em um dente de engrenagem da vasta máquina econômica - importante se dispunha de muito dinheiro, insignificante em caso contrário -, mas sempre um dente de engrenagem para servir a uma finalidade a ele alheia." (FROMM, 1968, p.95).

Ademais, a superficialidade metódica dos seus postulados impõe reduções e mesmo interditos ao tratamento mais crítico e conseqüente de questões primordiais da sociedade moderna e de suas espacialidades, dentre as quais à condição de uma massiva alienação socioespacial, promovendo inversões e distorções, ao mesmo passo que infunde a banalização da existência nos projetos de vida, com uma conformação espacial e urbana que Ihe dá sustentação. Vicejando sob a lógica do espetáculo autoritário do mercado e da mercadoria, a sociedade que tal sistema engendra é instada a conformar o uso relativamente livre do tempo e do espaço menos como uma aventura criativa e profícua, e mais como um uso cotidiano restringido e adaptado ao espetáculo, que dissocia trabalho e ócio. Assim,

[...] é essencial que o trabalho já de saída seja uma esfera separada, destacada do resto do contexto social. Quem trabalha apenas trabalha e não faz nada diferente disso. Descansar, divertir-se, seguir seus próprios interesses, namorar etc., isto tudo tem de acontecer fora do trabalho, ou pelo menos não pode ter um efeito perturbador sobre os processos funcionais plenamente racionalizados. É natural que isso nunca possa ter êxito por completo, porque o homem, apesar do adestramento secular, simplesmente não pode ser convertido totalmente em máquina. Mas fala-se aqui, sim, de um princípio estrutural que empiricamente nunca ocorre com pureza total. [...] Por esta razão, portanto, com base na exclusão de todos os momentos de não-trabalho da esfera do trabalho, a imposição histórica do trabalho caminha junto com a formação exterior de esferas sociais cada vez mais separadas, nas quais esses momentos cindidos são banidos; esferas que ganham elas mesmas um caráter exclusivo (no sentido enfático da palavra exclusão, por conseguinte, expulsão): tempo livre, privacidade, cultura, política, religião etc. (TRENKLE, 1998, s/p).

Nessa mesma direção, a vida estudantil é compelida ao culto automático e sub-reptício da cultura-mercadoria moderna e ao consumo delirante, azeitada por seus diálogos sem limites e pelo uso ostensivo da publicidade comercial, interferindo nos critérios da prática criativa cultural. Na sua representação de si mesma, ela impõe suas categorias ideológicas, que passam a nortear a compreensão do mundo e da história, embora percam cada vez mais sua coerência, sugerindo uma conspícua decomposição ideológica, percebida pela degenerescência de concepções de mundo que veiculam. Tais concepções, não raro, 
envolvem pensamentos reacionários, que ao opor os desiguais, amolda situações permanentes de conflitos, perturbação e iniqüidade. Poder-se-ia falar aqui da formação de uma oposição degradada e degradante, cujas reverberações ao plano teórico e prático acabam sendo naturalizadas, pois sem crítica consistente.

Estaríamos diante de um sistema instrumentalizado por uma pedagogia disciplinar, de feição autoritária e alienante, altamente burocrática e fetichizada, que mascara categoriais essenciais da realidade social, sugerindo-nos uma espécie de menopausa do espírito, interditando nos indivíduos a reconstrução dos desejos conquanto de um espaço como processos indissociáveis. Isso remete a uma condição de alienação, que se objetiva e recobre o próprio espaço, colocando-nos, assim, um problema existencial sensivelmente vinculado a ele. De sorte que:

“A objetivação é parte da condição humana, mas colocar-se separado do mundo é também fonte de alienação. $O$ estabelecimento de relações com o mundo, a ligação criativa entre sujeito humano e os objetos de seu interesse, constituiu uma tentativa de superar a alienação, mas também isso ameaça ser alienante, quando reduz o eu subjetivo, quando o sujeito é objetivado através das relações com o mundo. Assim, a alienação existencial é um estado de separação tanto de si mesmo quanto do mundo objetivo." (SOJA, 1993, p.163).

Esta pedagogia propõe-se a falar de "tudo", menos o que ela realmente é, isto é, mercadológica, fetichista, redutora, resignada às determinações do processo atual de globalização e, desse modo, ao desenvolvimento de uma sociedade da aparência e da imagem, carregada de forte ideologização. Destaca-se aqui a ideologia do enaltecimento dos objetos - melhor dizê-lo mercadorias -, que permeiam a nossa flutuante existência, mediando nossa relação com a(s) natureza(s) Bastante difundida no mundo atual, esta ideologia estabelece a redução do horizonte do futuro, suscitando a idéia de um "presente ampliado", o que praticamente interdita a sua percepção como uma outra coisa. (SANTOS, 2000, p.159). Ao plano da vida cotidiana ela responde pela constituição de uma forma social com subjetividades controladas. Em outras palavras:

"O relacionamento de um indivíduo com outro perdeu seu caráter direto e humano, assumindo um espírito de manipulação e instrumentalidade. Em todas as relações sociais e pessoais, as leis do mercado são a regra. É claro que o relacionamento entre concorrentes tem de ser baseado em mútua indiferença humana; do contrário, qualquer um deles ficaria paralisado na satisfação de seus encargos econômicos - lutar um contra o outro e não abster-se da efetiva destruição econômica do outro desde que necessária." (FROMM, 1968, p.101). 
Conforma-se, assim, uma "ordem social que espera do indivíduo apenas uma reação adequada (na base do sim/não) a estímulos programados". [...] "Nesta forma, saber definese basicamente como 'saber agir', isto é, corresponder por hábitos, reações prontas, aptidões, às expectativas da organização tecnocapitalista". (SODRÉ, 1990, p.40).

\section{A valorização da dimensão espacial na educação: um horizonte para a contemporaneidade}

Em face desta condição institucionalizada de embotamento e esterilidade das idéias e do espírito, urge forjar, ao plano fragmentário da vida cotidiana, uma nova forma de vida e do viver sob uma efetiva motivação humanística, orientada à criação de situações e ambiências mais dinâmicas, dotadas de maior sinergia entre os edifícios e demais objetos territoriais com seus usos práticos. Isso implica na valorização da função psicológica dos ambientes, conquanto na sujeição à crítica radical de leis e regras que entravam e/ou constrangem o desenvolvimento de práticas conseqüentes e mais eficazes na vida cotidiana e na cultura, incentivando-se, nesse sentido, a criação experimental de situações locacionais moventes de aglomeração lúdica e criativa das pessoas, de modo a estreitar as relações entre o ambiente e o comportamento, sob a clara determinação de transformação e superação da condição de esterilidade e amortecimento dos ambientes, que marca a crise do urbanismo capitalista contemporâneo. Esta condição não se reconhece, portanto, em conformações meramente funcionais e padronizadas, aspectos que matizam o urbanismo moderno e sua lógica de dominação sobre o espaço. Estes, sabidamente, constituem fonte de permanente mal estar e insatisfação sociais, impondo o ócio rotineiro e tedioso em meio a um consumismo desenfreado. Sob eles reduzem-se sensivelmente as possibilidades do movimento da vida e da existência, ambas esvaziadas de sentido e finalidade, ao mesmo passo que obliteradas pela sobrevivência sob o influxo redutor do ciclo da mercadoria e dos imperativos econômicos.

Sob a predominância de relações sociais de alienação - derivadas, sobretudo, do trabalho tutelado, subordinado e competitivo, que converte o concorrente em inimigo -, produzemse o que podemos qualificar de espacialidades insanas e da insanidade. Elas se constituem sob uma lógica da desconfiança generalizada, do ódio, do estranhamento das pessoas com o produto de seu trabalho, o que vale dizer de um estranhamento com o próprio espaço; espaço que, de modo geral, não resulta de demandas efetivas de seus habitantes, de seus 
usuários. É nesse sentido que a produção social do espaço comporta inteiramente o sentido do trabalho alienado, que matiza seus ambientes, modos de vida e representações. Estaríamos, assim, diante de realidades socioespaciais alheias aos desejos e necessidades das pessoas, conformando uma condição de dissociação relacional e banalização, sob o culto obsessivo do imediatismo e do consumo. Assim, a fragmentação, a segregação (e a autosegregação) e as desigualdades, que se recrudescem, refletiriam expressões socioespaciais da dissociação, aspectos insinuantes que indubitavelmente marcam o urbanismo e a urbanização hodiernos.

Acerca disso, ganha relevo o problema representado pela crescente quantidade de automóveis circulando pelas ruas, que se conforma como um dos maiores problemas do urbanismo na contemporaneidade. Processa-se a instauração de uma efetiva motorização da sociedade, que promove a conversão dos lugares em lugares de passagem, quase que eliminando a fruição da esfera do cotidiano, ao mesmo passo que impõe o declínio do caminhar. Desse modo, a cidade vai se transformando em espaço do isolamento socialmente consentido, com um ambiente estéril e amortecido, o que significa limites rigorosos à realização da vida em condições mais dignas. Compreende-se, assim, que o urbanismo contemporâneo procede a uma inversão perversa, isto é, uma orientação pela qual a cidade deve se ajustar às pressões da circulação motorizada, quando deveria ser o contrário, a circulação se submetendo às demandas da cidade e dos citadinos. O que vemos é a imposição da lógica da locomoção capitalista numa sociedade de consumo dirigido, que tem no automóvel o maior símbolo do individualismo da sociedade burguesa.

Segue-se daí que a extensão motorizada do raio de deslocamento diário dos trabalhadores nessa sociedade tem como contrapartida certa retração do horizonte de escolha de pontos de destino. Isto vale dizer que quem vai a pé ao trabalho cria para si um ambiente no seu percurso, e quem vai de carro se priva, em larga medida, de uma variedade de opções, tais como paradas, acessos, encontros, fruição paisagística, movimento do corpo para a saúde do organismo, da mente e do espírito.

O indivíduo motorizado, ou ainda "usuário circulante motorizado", em sua órbita pontual, repetitiva e diária, submete-se, assim, a uma relação alienada com seu espaço de vida (aqui incluído o de trabalho), não raro incapaz de vislumbrar maiores possibilidades quanto à constituição de um território livre e saudável, que seja capaz de promover o encontro e não a fragmentação/separação, a troca de valores afetivos e não apenas de valores de troca, que 
promova, enfim, a política e não a sua banalização. Dado que o motor e o acelerador mediatizam a sua relação com o meio-ambiente, amplia-se sua alienação em relação ao espaço, praticamente interditando uma percepção mais crítica sobre o lugar de vida.

O declínio do caminhar na sociedade moderna opera, certamente, como uma variável importante na promoção do isolamento e distanciamento entre as pessoas, constrangendo a vida pública e, dessa forma, a política. Neste sentido, não acreditamos, honestamente, que transformações sociais de fundo para uma nova e melhor condição socioespacial possam se desenvolver sob a proeminência da lógica da impessoalidade e da circulação motorizada.

A prioridade de um novo urbanismo, social e ambientalmente conseqüente, deve ser o pedestre e não o automóvel, perspectiva que não se reconhece numa arquitetura da cidade submetida à lógica da aceleração prepotente, que consolida a condição da anti-cidade nos meios urbanos, um cenário de mal estar generalizado, no qual as pessoas não se reconhecem e/ou não se identificam com a cidade.

O sentido dessa abordagem implica, portanto, no desvendamento da sociedade urbana em suas características atuais, o que solicita mais do que nunca considerações espaciais no encalço desse deciframento, em que pese o fato das sociedades estarem submetidas a ambientes cada vez mais artificializados e tecnificados, sob uma urbanização ampliada e extensiva, que se desenvolve contraditória e seletivamente sob os influxos da globalização capitalista contemporânea. Essa empreitada visa proporcionar a plena disposição à sociedade de condições e meios que favoreçam mudanças desejáveis e necessárias no espaço-tempo presentes, e aquelas que estão por vir, operando como um meio de conhecimento ao mesmo passo que uma perspectiva de ação. Este sentido não apenas significa a possibilidade real quanto ao controle dos caminhos a seguir, como igualmente da superação da passividade pela ação transformadora consciente. Seu propósito é tanto mais importante quanto à afirmação da vontade de criar, entrevendo as satisfações necessárias imperiosas.

Estamos convencidos que a perspectiva dialética é o único método capaz de imprimir-lhe este sentido, pois conducente a uma compreensão superadora, que permite lidar com a esperança na contemporaneidade, portanto com o desejo - insubmisso ao espetáculo a ao funcionalismo atuais - que aspira a uma condição humana melhor e descontínua, logo de uma espacialidade mais favorável à totalidade da vida, tangível a toda a sociedade. E é no desvendamento das contradições da vida cotidiana que os sinais da esperança podem ser 
encontrados e reconhecidos, trazidos à tona pela teoria crítica, teoria que não deve se restringir tão somente à mente de pensadores e intelectuais, senão objetivando-se como uma força prática. Não escapa à prescrição de sua utilização consciente seu aspecto ativo, que pode inspirar ou nortear a ação, portanto a experiência social e humana, presente e futura, que se desenrola no e pelo espaço. Dado que a educação é, em certo sentido, a matriz da política, ela se abre então ao campo da crítica social e da existência, sobretudo no que importa à sua dimensão qualitativa, não se restringindo tão somente a simples denúncia de injustiças sociais - pondo às claras as estruturas de dominação, de exclusão (e de inserção perversa), de alienação (inclusive para com o espaço) - mas, acima de tudo, problematizando-as quanto às possibilidades factíveis à sua resolução e superação.

Não obstante é preciso ter clareza quanto ao fato de que nenhuma transformação social efetiva logrará êxito sem a concomitância da transformação espacial, o que demanda atos práticos, ações insurgentes, isto é, uma efetiva inserção ativa na sociedade, no sentido de se forjar percursos socialmente mais desejáveis em face de conformações socioespaciais desiguais. Lançar-se-iam, assim, condições ao desestímulo ou mesmo à neutralização de posturas de acomodamento e consentimento às práticas de mortificação do espaço reinantes, estimulando-se ações de (re)apropriação dos lugares mais sintonizadas com demandas socialmente desejáveis, não raro reprimidas, requalificando e revalorizando-os ao plano da existência e da necessidade de existir, conformando-os como efetivos domínios de liberdades humanas.

Essa perspectiva sugere uma aposta na vida como objeto maior, como única instância - ela antes de todas as coisas - forjando-se uma cartografia de situações de outros possíveis mundos, pelos interstícios e brechas da tessitura espacial mercadológica e empresarial, já havendo no mundo atual manifestações de certa expansão insidiosa de práticas dotadas de um caráter insurgente, capazes de transformar e reapropriar espaços públicos, mobilizando agentes ativos de variados matizes (cuja atuação e presença recobrem tanto áreas centrais como periféricas da cidade). Dentre elas podem-se mencionar movimentos e manifestações artísticos e culturais de arte e música, entre outras. Sob essa perspectiva, o território e os lugares convertem-se em objetos de ações, ou ainda um produto delas. São ações produtoras de novas situações, com a criação de ambientes de caráter mais coletivo vivenciada por seus próprios construtores e vivenciadores, afirmando-se, assim, outras e mais desejáveis realidades socioespaciais. Essa condição se apóia tanto na idéia de esforços 
partilhados (mais incisivos) à consecução de condições imprescindíveis à vida e a existência, como na de sobrevivência, que adquire certa centralidade sob o recrudescimento da disputa e da competitividade do capitalismo globalizado.

Essa perspectiva prescreve um novo sentido ao desejo, agora organicamente imbricado ao espaço, dele não mais prescindindo. Embora o desejo remeta a uma situação futura, referenciando-se a algo que ainda não se realizou ou se cumpriu, ele, bem entendido, não significa a perda ou o descarte do essencial da vida no tempo presente, antes, ao contrário. (COMTE-SPONVILLE, 2001). Um aspecto crucial à realização deste percurso é a valorização do princípio político da autogestão, afastando-se, portanto, da submissão ao Estado e ao mercado e, assim, do objetivismo, tanto o de resultados (identificação de supostos problemas e imperfeições da sociedade) como o objetivismo idealizado (mais ao plano da gestão de concepções e opiniões), que dão o tom de suas práticas - bastante articuladas, aliás. Isso não significa uma via orientada à supressão do Estado, ou à recusa de alguma forma de autoridade válida e legítima. Trata-se, mais propriamente, da constituição gradativa de uma realidade socioespacial na qual a sociedade possa, efetivamente, fazer valer democraticamente suas próprias demandas e desejos frente às instituições, forjando a sua própria transformação, sujeitando-as, portanto, ao seu pleno controle. Mobiliza-se aqui o desejo para a transformação de nossas subjetividades, práticas e comportamentos em prol de uma vida e existências mais plenas, pelas quais somos responsáveis. No que importa ao território, isso significaria que o urbanismo fosse conduzido "de baixo para cima", forma pela qual os técnicos traçariam os planos urbanísticos a partir de demandas sociais efetivas, levando-se em consideração realidades sensíveis do universo de sentimentos das pessoas. Isso implicaria na promoção de situações urbanas excitantes e estimuladoras, agindo sobre o comportamento e demais aspectos desejáveis da transformação dos hábitos.

Criação de novas formas, reapropriação e ressignificação de construtos já consolidados, em moldes socialmente desejáveis, configurariam um novo horizonte e uma nova condição à espacialidade urbana contemporânea, aspectos que intersticialmente podem ser identificados em movimentos organizados de moradores na luta pela preservação de patrimônio arquitetônico-urbanístico e certos aspectos do universo de relações de bairros, e de seus modos territoriais de vivência, que remetem ao plano da vida cotidiana. Isso não se confunde um utopismo ingênuo e muito menos de hipostasiamento da realidade, ou de negação do real em nome de um ideal, mas sim da valorização de práticas e atores que 
sugerem não apenas certa resistência aos efeitos corrosivos da globalização capitalista (sobre o pensamento, a política e a vida, portanto sobre o espaço). Elas representam descontinuidades aos moldes territoriais hegemônicos, com virtualidades a formas de vida mais intensas, mais ricas em diversidade, capazes de se organizar e evoluir sob a influência e a interferência direta dos próprios interessados. E, ousamos dizer, só assim o espaço será aceitável. E isso não é uma questão de gosto ou de preferência, mas de necessidade imperativa de sobrevivência e existência, com um maior interesse na cooperação e na harmonia relacional do que no consumismo desenfreado, conflito e guerra. É necessário, pois, melhor identificá-las, conferindo-lhes maior visibilidade, de modo a enriquecer o horizonte de possibilidades a outras vias, reduzindo ou mesmo relativizando o espaço de interferência redutor e mistificador do pensamento único à análise e às práticas sociais interferência que tem conduzido a uma situação de controle das próprias subjetividades.

Reafirma-se a convicção de que mudanças de fundo na espacialidade contemporânea só virão com o desejo pela liberdade e pela vida em sentido pleno, um desejo profundo da maior intensidade possível, a uma vida que não seja mais empobrecida e dilacerada, antes, pelo contrário, a vida mais plena que se possa ter, erigida num anti-valor, ou seja, no puro afeto entre as pessoas. Nesse sentido, sustenta-se que não há vida verdadeiramente satisfatória sob a lógica de um espaço-tempo mortificante, regida pelo econômico como fator dominante ou exclusivo.

Abre-se, assim, um horizonte político-crítico à educação na contemporaneidade, que não prescinde do espaço, antes reafirma a sua importância; uma efetiva educação espacializada para a vida, eis do que se trata. Ela se orienta à superação de racionalidades segregadoras que, ao nortear práticas de ordenamento territorial, expulsam ou interditam o acesso ao espaço (tornado mercadoria), condição que está na base da suburbanização. Esta educação envolve o gosto e o interesse pela solidariedade, pelo convívio e interação com as diferenças, ou ainda, pelo prazer ao invés do lucro, pela alegria ao invés do medo ou da obsessão pela morte. Medo e morte, aliás, tornados matérias-primas preferenciais da pedagogia "indiferente" da mídia e do jornalismo do espetáculo e do escândalo, cuja veiculação se justifica [...] "por sua própria circulação, pelo mero trânsito num meio", que alimenta uma "ideologia tecnicista”, "circulatória" ou "mediática”. (SODRÉ, 1990, p.39-40). Diante de uma vida cotidiana esvaziada de substância e sentido, resta falar das pessoas, o que se traduz em ações diversas de futrica que permeiam todas as instâncias do poder, 
infundindo uma espécie de falocracia da intriga, que se dissemina em escala global. Ao plano do cotidiano, o medo (associado à violência) parece nos reger, ainda que não tenhamos plena consciência disso; e, para além das múltiplas evidências empíricas que geram o medo, a mídia do espetáculo e do sensacionalismo, profusa neste mundo dominado pelo cotidiano, ao conferir-lhe certa centralidade e destaque, promove sua ampliação nas mentes, o que sugere artificialismos sobre a questão. Uma sociedade acuada, paranóica e intolerante emerge das entranhas deste cotidiano, nele se enredando dissociativamente, com expressões sob a forma do espetáculo multifacetado.

Por outro lado, a constituição de uma educação espacializada significaria uma alternativa, se não uma perspectiva de superação da produção burocrática do condicionamento, portanto da planificação urbana de caráter mercadológico, que opera a cidade como um negócio. Sob sua lógica os segmentos sociais são instados à legitimação consentida de ações de inserção individual na urbe em detrimento de ações coletivas e democráticas.

Esta condição de fragmentação e esterilidade socioespacial não se mostra absoluta, embora dominante, mas as lutas e práticas que incitam sinalizam a uma reavaliação crítica dos próprios parâmetros da humanidade, quando o econômico e as questões econômicas assumem proeminência sobre as relações sociais a escala planetária, modulando-as. Esses vetores insurgentes pluralizam o campo de forças da contemporaneidade, imprimindo-Ihe uma condição temporal mais flexível e dinâmica, não linear, conferindo-lhe um novo estatuto temporal, que requalifica o presente enquanto momento histórico, submetido à incidência de uma multiplicidade de experiências e suas virtualidades.

Para além de problematizar criticamente o espaço existente, suas conformações materiais e as lógicas que norteiam sua formação e ordenamento, uma educação espacializada - que recobriria uma educação política do próprio espaço - se debateria com as possibilidades factíveis quanto à produção de novos espaços e de novas modulações territoriais. Estas seriam mais influenciadoras e sintonizadas com os desejos humanos, sob uma concepção mais dinâmica das formas, dado que estão em permanente mutação. Isso significaria a abertura de um horizonte a práticas experimentais, de modo a compor cartografias intersticiais alternativas dotadas de um caráter propositivo, ao mesmo passo que reativo. Ou seja, o lugar não se modifica apenas pelo gosto ou pelo pertencimento a ele, mas fundamentalmente por ações no/do lugar precipitadas pela necessidade (ou por necessidades que clamam), o que envolve a própria resistência face ao modelo global 
neocapitalista - que submete ao seu aparato de controle territórios, Estados, estruturas científico-técnicas, fluxos e demandas de capital.

A criação desse horizonte implica, assim, no reaprendizado quanto às formas de uso e apropriação do espaço, de modo à melhor explorar suas potencialidades em termos de valor de uso, com novos modos de usar e experienciar o espaço e os lugares como atos do desejo e da vontade livre, portanto não circunscritos aos padrões engessados de finalidades previamente demarcadas, mas abertos às demandas da necessidade. A apropriação é aqui entendida como situação referenciada aos diversos modos pelo qual o espaço é ocupado, quer por formas materiais (objetos), quer por atividades inscritas territorialmente (que configuram os usos da terra), e ainda por indivíduos e segmentos sociais variados. Esta condição implica a adoção de estratégias e práticas devotadas à superação das formas de condicionamento socioespacial, conduzidas pelos interstícios dos lugares, de forma a que se tornassem células territoriais de afirmação da liberdade, pelas quais se forjariam novos sistemas relacionais, deslocando-se, gradativamente, formas de isolamento e segregação induzidas. O que não significa a eliminação de conflitos e lutas, dado que mudanças e transformações de fundo virão, sobretudo, com eles.

O sentido dessa perspectiva reforça o entendimento de que a cultura do econômico e do capital (aqui entendido como relação social baseada na mercantilização da força de trabalho) não submeteria plenamente a sociedade na sua totalidade e diversidade; nela, o que não é racional ou racionalizado é residual; mas esta cultura é crítica, fonte de tensões diversas, que enfrenta tanto a diluição como a recriação de fronteiras (veja-se, por exemplo, a proliferação de condomínios fechados monitorados), mas também a insurgência explosiva de guetos e bolsões de pobreza, e o avanço de estruturas paralelas de poder.

Nesse sentido, assume importância fundamental a fecundidade de experiências socioespaciais livres - as quais efetivamente prescrevem sentido à vida -, resistências insurgentes ativas que operam de forma mais autônoma, mobilizando o imaginário (aquilo que potencialmente pode se tornar real) e simbolismos em suas práticas. Estas, em seu conjunto, representam a politização do uso, projetando no horizonte a possibilidade da construção de territórios de utopia luminosa, do supostamente impossível se realizando em algum lugar. Um bom lugar para se viver, eis o seu melhor sentido. Ressalve-se que o destaque ao local e ao interstício não significa a fetichização dos mesmos. Além do mais, sob 
as condições atuais de um amplo desenvolvimento das redes, os lugares potencializam inserções no global, havendo entre eles uma relação de mútua determinação.

Por contraste, a urbanização extensiva do capitalismo está na base de processos de dissocialização e degeneração de comunidades, conduzindo à degradação do próprio homem e a um enorme desperdício de extensões consideráveis de área construída - que não apenas comprimem e obstruem demandas urbanas importantes, por vezes urgentes, como explicitam a banalização (e a alienação) do trabalho e a irracionalidade do investimento (inclusive público!). Com efeito, é plausível admitir que esta espacialidade, que comporta inteiramente o sentido do trabalho alienado, carregue o sentido de uma crise, crise que recobre e reflete a crise do próprio trabalho. Trata-se de uma espacialidade crítica, em que pese a preponderância do valor de troca e o caráter coercitivo que lhe é inerente, aspecto fundamental da alienação do espaço. A proeminência centralizadora alcançada pelo valor de troca, para além de insinuar-se como abuso e distorção, representa um fator de degradação e fragmentação socioespaciais, impulsionando a criação artificial de necessidades ao mesmo passo que de uma sociabilidade abstrata, que recobre aspectos de homogeneização permeados por fragmentos dispersos. Estes, impelidos pela lógica da valorização, tornam-se progressivamente funcionais ao progresso técnico, mostrando-se principalmente na desconcertante espacialidade metropolitana, que assim se conforma como uma espécie de reino do homem-coisa.

\section{Uma perspectiva político-espacial à educação: desejo, liberdade e autonomia}

Esta perspectiva político-espacial à educação conforma, assim, um pensamento, pois busca uma possibilidade e, desse modo, um sentido, que se põe em movimento sob a luminosidade do desejo, que mobiliza o desejo profundo pela liberdade, tanto quanto ela seja possível. É preciso, pois, tomar a liberdade não como um meio, mas como um fim, ou ainda como uma condição ao alcance de um propósito, algo socialmente desejado, e não somente como liberdade de alguma coisa. (HELLER, 1982, p.155). Com efeito, ela implica perspectiva e caminho, portanto teleologia. Dado que a liberdade é uma relação social, ela solicita esforços permanentes de ampliação e lapidação, o que demanda atos práticos, tornando-se, desse modo, uma questão política. Traduzindo-se como uma condição socialmente construída e efetivamente conquistada, ela significa, antes de qualquer coisa, a 
capacidade de agir para além dos interesses particulares, abrindo-se, portanto, ao reconhecimento do outro, logo da diferença, sendo o limite desta qualquer forma ou expressão que deponha contra o ser humano. Eis o limite fundamental à diferença, uma vez que nem toda diferença é socialmente aceitável, havendo expressões absolutamente inadmissíveis, grotescas, ameaçadoras. Não se pode perder de vista, ainda, que a liberdade constitui um valor essencial e imprescindível à mudança, sem a qual se reduzem substancialmente as possibilidades de um efetivo desenvolvimento social, o que significaria energia abundante à manutenção de um cotidiano marcado pelo mal-estar, pelo tédio e pela glacial ausência de sentido à vida.

Sob a perspectiva de formação de uma sociedade mais autônoma, a ênfase educativa à promoção de formas alternativas de uso e apropriação do espaço poderia representar o limite e a possibilidade de superação da alienação, pois conducente - pela crítica e ações à criação de situações no mundo prático-sensível (estreitamente vinculadas aos lugares) - à redefinição de sentidos e funções de construtos socioespaciais já existentes, revalorizandoos pela necessidade e por tudo que se faça necessário a uma vida mais plena, intensa e digna.

Isso significaria, então, encontrar ou mesmo forjar um novo sentido à vida, diferente e sensivelmente melhor, o que não se confunde com um descarte de modos de vida pretéritos e/ou tradicionais, antes recuperando e valorizando-lhes quanto ao que possuem em benefício de uma vida melhor, e não de sua negação ou redução. Este novo sentido requer a superação do individualismo burguês, enraizado no egoísmo e na concorrência mercadológica, aspectos tornados princípios fundamentais para a conquista do poder na sociedade atual. As situações produzidas pelos interstícios do espaço e da cidade carregam virtualidades capazes de lhe imprimir um sentido de ruptura ao urbanismo funcionalista capitalista, operando como genuínas células dinâmicas de caráter liberatório.

Nesse sentido, a instauração de uma desejada sociedade autônoma, segundo Castoriadis (1999, p.83), não poderia se dar

[...] senão pela atividade autônoma da coletividade. Uma tal atividade pressupõe que os homens invistam fortemente em outra coisa além da possibilidade de comprar um novo aparelho de televisão em cores. Mais profundamente, pressupõe que a paixão pela democracia e pela liberdade, pelos negócios comuns, tome o lugar da distração, do cinismo, do conformismo, da corrida para o consumo. Em resumo: ela pressupõe entre outras coisas, que o "econômico" pare de ser o valor dominante ou exclusivo. É esse [...] o "preço a pagar" para uma transformação da sociedade. Digamo-lo mais claramente 
ainda: o preço a pagar para a liberdade é a destruição do econômico como valor central e, de fato, único.

Será um preço assim tão elevado? Para mim, seguramente não: prefiro infinitamente ter um novo amigo a um novo carro. (destaques do autor).

Portanto, apenas com efetivas condições de liberdade é que poderemos ter uma sociedade autônoma e uma vida intensa e completa. Sua negação implica na promoção do autoritarismo, da dominação e do condicionamento, refratários ao efetivo desenvolvimento humano - o qual só encontra capacidade de realização sob plenas condições de emancipação.

O desenvolvimento da modernidade representou a afirmação e a difusão da racionalidade capitalista no espaço, consubstanciando-se em pressuposto da rentabilidade, operando pelo cálculo sistemático e metódico, que é o cálculo do ganho, no sentido capitalista. Esta racionalidade constitui uma ideologia e um modo de pensar e ver o mundo, dominando e modelando as subjetividades. Com notável capilaridade no universo das relações socioespaciais, ela estabelece uma redução fundamental nesta sociedade: a de qualidade em quantidade, impondo uma ordem objetiva das coisas, que é a das leis econômicas e do mercado. Compreendendo uma forma abstrata de dominação, ela se amplia, realizando-se por estruturas hierarquizadas, com uma eficiência cada vez mais aprimorada na exploração dos recursos humanos e naturais, conformando uma condição permanente e continuada de exploração do trabalho para o aumento progressivo da riqueza de mercadorias. (MARCUSE, 1969). Ela dispõe de uma espacialidade igualmente racionalizada e racionalizante, dado pelo urbanismo capitalista, que consolidou a prevalência do ter ao ser, do valor de troca submetendo o uso. Mais, cada vez mais, é o sentido - produtivista - desta racionalidade, cuja dominação tornou-se sistêmica, totalitária, tirânica, pois opera mediante um sistema de coordenação e manipulação que se estende a praticamente toda a sociedade, reduzindo-lhe sensivelmente a autonomia e a liberdade, não obstante faça parecer o contrário. Conformase, assim, uma irracionalidade tornada razão, que se consubstancia como um fim em si mesmo. Sob sua lógica,

"O mundo tende a tornar-se o material da administração total, que absorve até os administradores. A teia da dominação tornou-se a teia da própria razão, e esta sociedade está fatalmente emaranhada nela. E os modos transcendentes de pensar parece transcenderem a própria razão." (MARCUSE, 1969, p.162). 
Esta mesma racionalidade só se mostra refratária a alternativas que coloquem em xeque a sua lógica (autista), a práticas que apontem para a sua superação, opondo-se, portanto, somente a mudanças radicais. Daí poder-se dizer que o espaço e a vida estão longe de constituírem sistemas fechados e acabados, pois essencialmente abertos às possibilidades da política, a qual, apartada da ideologia, pode tornar-se uma força efetivamente crítica e transformadora.

"Se o espaço é a esfera da multiplicidade, o produto das relações sociais, e essas relações são práticas materiais efetivas, e sempre em processo, então o espaço não pode nunca ser fechado, sempre haverá resultados não previstos, relações além, elementos potenciais de acaso." (MASSEY, 2008, p.144).

Uma vez que a educação, por si só, revela-se insuficiente para mudar os rumos da história, sem ela, temos a convicção, tornar-se-á imponderável a construção de um mundo melhor e mais solidário, um mundo cuja centralidade não seria o mercado e o dinheiro, mas o homem e suas verdadeiras necessidades, não aquelas artificialmente criadas pelos veículos de publicidade a serviço do consumismo desenfreado.

Desnecessário seria apontar constrangimentos de toda ordem que recaem sobre a vida cotidiana de nossos tempos. Negligenciá-los, contudo, constituiria um ato de deserção. É nesta perspectiva que, a despeito de qualquer forma de dirigismo sobre as mentes, se reafirma a necessidade de uma ação educativa que não circunscreva o papel da escola à reprodução das relações de poder, não subordinada, portanto, ao sistema de exploração e controle atual. Esta ação deve ser pautada por uma perspectiva efetivamente humanista de caráter transcendente. Acerca disso, e a propósito, caberia indagar se seria possível uma genuína educação que não fosse humanista. Compartilhamos da idéia que uma verdadeira educação é necessariamente humanista, na medida em que se devota à formação da humanidade do homem, de sua integridade e espírito crítico, capacitando-lhe a conviver e a aceitar as diferenças, mas não as desigualdades. A genuína educação, portanto, não se reduz e muito menos compactua com práticas produtoras de autômatos e alienados social e espacialmente, conformados e submissos à lógica do capital e ao mundo encantado da mercadoria.

Sob os imperativos da necessidade e do desejo somos instados a uma aferição crítica quanto aos limites e as possibilidades de criação de um novo homem e de uma nova humanização, não no sentido de uma melhor capacidade analítica e argumentativa, mas mais 
propriamente indagando e perquirindo modos mais adequados de responder à questão do sentido da vida, o que solicita um pensamento ampliado que recubra a auto-reflexão permanente e a percepção lúcida da alteridade. É nessa perspectiva que uma ética existencial orientada à preservação da vida e da restituição qualitativa dos valores humanos constituiria um pressuposto imprescindível à produção de uma nova via ao homem e de um mundo mais solidário e cooperativo, desembaraçado de ilusões e da morbidez.

Ações insurgentes à criação de situações, dotadas de caráter cooperativo e autônomo, constitui um genuíno valor educativo a estimular a produção de novas formas de organização societária, logo socioespaciais, bem como arranjos institucionais mais consensuais e adequados às demandas da sociedade, operando como fator galvanizador daquelas ações. Desse modo, os desafios impostos pelas novas práticas e conformações socioespaciais em curso, reafirmam a necessidade de esforços permanentes na superação de estruturas materiais e institucionais produzidas sob a lógica preeminente do mercado e do lucro, que responde conspicuamente pelo recrudescimento de desigualdades e privações de liberdade, tornada, assim, liberdade para o mercado.

\section{CONSIDERAÇÕES FINAIS}

O que nos parece fundamental destacar aqui acerca do sentido desses apontamentos, é o fato de que a história não apenas continua, como, ousamos dizer, apenas começa, com um horizonte aberto de ações, projetos, desejos e intenções, como algo, enfim, que pode ter sentido. O homem, definitivamente, não é um ser acabado, e a história está longe de ser uma via de mão única, como sugere o discurso conveniente e adaptado dos fariseus de plantão, servos do dinheiro fácil e da racionalidade mercantil. Para esses a história acaba aqui. Destituídos de maiores ambições, socialmente qualitativas, sua única preocupação é o conformismo frente às determinações do processo atual de globalização. É nesta perspectiva que a idéia de história, sentido e destino é profusa e reiteradamente amesquinhada em nome de metas estatísticas, induzidas e estabelecidas pelos agentes hegemônicos do capital e as instituições que os representam e defendem os seus interesses.

A história se desenvolve a passos largos e sob novas condições, realizando-se de forma multidimensional, sob contradições recrudescidas e descontinuidades, suscitando possibilidades de reinvenção da experiência humana e do aprendizado da vida; vida aqui, 
bem entendida, no sentido de que nos fala o escritor e poeta Rimbaud, de que a "verdadeira vida" não se restringe aos fundamentos das necessidades utilitárias - às quais ninguém consegue escapar -, mas na plenitude de si e na qualidade poética da existência, haja vista que a realização da vida solicita de cada um de nós a concomitância da lucidez e da compreensão, conquanto da mobilização de todas as nossas aptidões.

Neste sentido, é que se pode valorativamente pensar com Santos (2000, p.164-165), ao dizer-nos que:

[...] jamais houve na história sistemas tão propícios a facilitar a vida e a proporcionar a felicidade dos homens. [...] Os novos instrumentos, pela sua própria natureza, abrem possibilidades para sua disseminação no corpo social, superando as clivagens socioeconômicas preexistentes. [...] As famílias de técnicas emergem com o fim do século XX - combinando informática e eletrônica, sobretudo - oferecem a possibilidade de superação do imperativo da tecnologia hegemônica e paralelamente admitem a proliferação de novos arranjos, com a retomada da criatividade. Isso, aliás, já está se dando nas áreas da sociedade em que a divisão do trabalho se produz de baixo para cima. Aqui, a produção do novo e o uso e a difusão do novo deixam de ser monopolizados por um capital cada vez mais concentrado para pertencer ao domínio do maior número, possibilitando afinal a emergência de um verdadeiro mundo da inteligência. Desse modo, a técnica pode voltar a ser o resultado do encontro do engenho humano com um pedaço determinado da natureza - cada vez mais modificada -, permitindo que essa relação seja fundada nas virtualidades do entorno geográfico e social, de modo a assegurar a restauração do homem em sua essência.

Nas condições atuais, esse propósito requereria então a necessária comunhão da técnica com a política, tendo em vista o embate e a transformação/superação das adscrições socioespaciais fixadas, bem como pela implementação de usos mais adequados e orientados às efetivas necessidades humanas, aqui incluídas as necessidades radicais - dentre as quais a liberdade -, que não se confundem com necessidades artificialmente criadas por veículos de publicidade a serviço do mercado e do capital.

Impõe-se a mobilização da esperança e dos desejos na construção de uma visão lúcida e sistêmica do universo de iniciativas e práticas que se anunciam no presente, as que sugerem caminhos e possibilidades à construção de um outro e melhor mundo possível, sintonizadas com a formação e o desenvolvimento de espaços alternativos de poder, que valorizam a democracia como condição fundamental a transformações socialmente desejadas. A geografia tem realizado esforços auspiciosos nesse sentido, contribuindo qualitativamente para esse projeto coletivo. Os desafios à consecução de uma vida mais plena e profícua demandarão ações transformadoras essenciais no modo dominante de vida e de sua socialização, portanto uma via radical no sentido de uma política efetivamente 
emancipadora, que se realiza sob um horizonte temporal mais extenso, mais demorado. Sob condições mais efetivas à liberdade, que vêm não sem conflitos, os indivíduos podem construir sua própria história e seus próprios espaços, fazendo prevalecer a vida em detrimento dos vetores da morte, o que vale dizer revogar, pelos interstícios e margens da sociedade, a lógica autofágica e de definhamento da mercadoria.

\section{REFERÊNCIAS BIBLIOGRÁFICAS}

CASTORIADIS, C. (1999) Feito e a ser feito: as encruzilhadas do labirinto V. Rio de Janeiro, DP\&A. 302p.

COMTE-SPONVILLE, A. (2001) A felicidade, desesperadamente. São Paulo, Martins Fontes. $139 p$.

FROMM, E. (1968) O medo à liberdade. 6a. edição. Rio de Janeiro, Zahar Editores. 235p.

HARVEY, D. (1992) A condição pós-moderna. São Paulo, Edições Loyola. 349p.

HELLER, A. (1982) Para mudar a vida: felicidade, liberdade e democracia. São Paulo, Brasiliense. 204p.

KOTANYI, A.; VANEIGEM, R. (1997) Programa elementar de urbanismo unitário. Boletim n.o 6, agosto de 1961. In: Internationale situationniste. Paris, Fayard. p.214- 217.

MASSEY, D. (2008) Pelo espaço: uma nova política da espacialidade. Rio de Janeiro, Bertrand Brasil. 312p.

MARCUSE, H. (1969) Ideologia da sociedade industrial. Rio de Janeiro, Zahar Editores. 238p.

RECLUS, É. (1985) A natureza da Geografia: o homem é a natureza adquirindo consciência de si própria. In: ANDRADE, Manuel. C. de. (org). Élisée Reclus. São Paulo, Ática. p.38-40. (Tradução de Maria Cecília França). 
SANTOS, M. (1996) A natureza do espaço: técnica e tempo, razão e emoção. São Paulo, Hucitec. 308p.

SANTOS, M. (2000) Por uma outra globalização: do pensamento único à consciência universal. São Paulo, Record. 174p.

SODRÉ, M. (1990) A máquina de Narciso: televisão, indivíduo e poder no Brasil. 2aa. edição. São Paulo, Cortez. 141p.

SOJA, E. (1993) Geografias pós-modernas: a reafirmação do espaço na teoria social crítica. Rio de Janeiro, Jorge Zahar Editor. 324p.

TRENKLE, N. O que é o valor? A que se deve a crise? Disponível em: http:// www. antivalor.vilabol.uol.com.br/textos/krisis/trenkle/tx_trenkle_013.htm. Acesso em 10 de setembro de 2010. (Tradução de Cláudio Roberto Duarte, com o auxílio de Heinz Dieter Heidemann). 